\title{
Tension of Legacy: Self-Authorship of Female Engineering Students and Their Professional Choice
}

\section{Dr. Jennifer A. Skaggs, American University in Cairo}

Assistant Professor in the Graduate School of Education and co-Director of the STEAM Center at The American University in Cairo, Egypt. Jennifer earned a Ph.D. in higher education with a concentration in gender studies from the University of Kentucky and received her MS in College Student Development from Miami University, OH. Her research focuses on: Student identity and development; Cultural issues in undergraduate STEM/STEAM education; International social foundations including epistemological beliefs related to critical pedagogy; Comparative international STEM/STEAM education, accessibility and policy; accreditation and assessment. 


\section{Tension of Legacy: Self-Authorship of Female Engineering Students and Their Professional Choice}

Being a successful female in engineering involves more than just mastering curriculum and technical competencies. It also involves learning how to negotiate one's personal identity as one's "professional engineering identity" is also being developed. Gender and technology are in a symbiotic process constantly being reconstructed in a dynamic and relational manner with the individual and the environment. The culture of technological work and its environment are associated with masculinity and power, both on a personal and societal level, ${ }^{1}$ leaving females out of the equation and without influence, control or authority. Schooling, including undergraduate engineering education, also reproduces gender divisions within educational institutions, thereby reproducing these imbalances within the professional workforce. ${ }^{2}$

By asking distinctive questions regarding how female undergraduate engineering students perceive and negotiate their gender identities in the male gendered environment of engineering education, this study allows for increased understanding of their identity development in relation to their future career choices. For many females, their identity formation during their college career, as they balance being a woman with being an engineer, is precarious resulting in an exodus of females from engineering within the first five years of graduation.

This paper will first present the research surrounding evidence of women not participating in engineering, indications of engineering as a socially-constructed masculine environment, and the purpose of higher education for professional and personal identity development. Secondly, the conceptual framework and research questions driving this study will be provided. Thirdly, Marcia Baxter Magolda's theory of self-authorship ${ }^{3}$ will be introduced as the theoretical framework for looking at the individual through the lenses of context and institution, as well as the larger cultural paradigm. Next, the methodological framework informing the research design and the research design and methods used throughout this study will be offered. Finally, the research findings of identity development and formation of females who have persisted in undergraduate engineering programs and how this impacts their professional choices will be discussed.

\section{Literature Review}

Research reflects increased enrollments of females in STEM majors; for example, women make up the majority of those studying the physical and life sciences (57\%). Yet the proportion of STEM major females in the high-profile STEM major of engineering is disproportionately low (18\%) compared to STEM major males pursuing engineering degrees (48\%). ${ }^{4}$ Additionally, it has been reported by the National Science Foundation that although an increasing proportion of the U.S. workforce consists of females (47\%), they make up only $26 \%$ of the STEM workforce, and only $11 \%$ of the engineering workforce. ${ }^{5}$ This demonstrates that while there is low involvement of females in engineering education, even less are involved in the engineering workforce.

The theoretical implication of this study is concerned with the lack of gender awareness, especially on the cultural level. It is necessary to look at the environment of the larger societal 
culture. Social discourse determines how men and women are supposed to play out their socially sanctioned roles. ${ }^{6}$ The females in engineering are constantly battling this social discourse as they strive to develop their authentic personal and professional identities even when the gender issues are not overtly evident.

\section{Social Constructions of Gender and Technology}

It is vital to understand technology as being shaped by society rather than the other way around. Technology is intertwined with our culture and has values embedded within it that help to shape society. Bijker \& Law describe how engineers and scientists conduct their research and establish and control the very latest technology with new knowledge and design. ${ }^{7}$ Technology is chosen and mediated by those in social power and domination, which has traditionally been an exclusively male domain. ${ }^{8}$ This domination has led to a monopoly of male engineers in control of the technological knowledge and its power upon society. Male dominance in technology and engineering has rendered gender invisible in the science of design and technology. There is a danger in this rendering as it assumes gender as being non-relevant within the social creation of technology. Yet, "universities still tend to reproduce this professional engineering culture and the corresponding social habit in favor of men" 9 resulting in research and design laboratories as primarily male dominated spaces. These are cultural environments where gender is not noticed unless females are present, implying that "as long as women do not appear as important actors or a relevant social group, gender is not a relevant category". ${ }^{10}$ The hazard of assuming the culture of technology is gender-neutral leaves little room for how factors of gender affect the experiences of women. It is necessary for gender to be acknowledged as an analytic category in order to be observed.

Just as technology is socially constructed, so is the concept of gender. The notion of gender and sex being distinctive from each other is widely accepted among scholars and academicians. Gender is viewed as being socially constructed, something that is "done" while sex is viewed as being biologically determined. ${ }^{11}$ One cannot choose not to participate in gender and one cannot choose not to participate in the "doing" of masculinity or femininity, as those are the only choices offered in our society. Gender identity is something everyone has and it is a dynamic variable which shifts and changes depending upon the different contexts and environments. Gender is not essential or natural; it is the various acts of gender that create gender. Gender is a performance; it is what someone does, not who s/he is. ${ }^{12}$

There is a societal position that supposes several irrefutable concepts regarding gender, including the beliefs that there are two genders (masculine and feminine) and biological sex organs determine gender. ${ }^{13}$ Dividing society into the binary forms of gender (masculine/feminine) and sex (male/female) is culturally second nature. Yet it is imperative to understand that masculine and feminine or maleness and femaleness are not simple set categorical characteristics, but rather a continuum along which individuals locate themselves in terms of self-identity. ${ }^{14}$ Within groups of men and women there is a lot of diversity in how gender is manifested and this diversity within the two groups allows for overlap between the genders with females acting more masculine and males acting more feminine depending on their placement on the continuum. Understanding the concept of this continuum allows for a pluralizing of masculinities and 
femininities breaking down the "binary opposition between male and female" 10 and allowing for "creative interrogation of the ways in which people 'do' gender". ${ }^{15}$

\section{Engineering as Masculine}

After World War I, engineering was, according to Ruth Oldenziel, a "project in masculinization". 16 The word "engineer" was originally given to the military troops who created, built, and operated machinery [engines] of war. ${ }^{17}$ This link between military and engineering has led to construction of a hegemonic masculinity that pervades the professional and educational environments of engineering. The term hegemonic refers to the cultural ideal of masculinity that is dominant and is associated with men who are in power. ${ }^{18}$

Not only is this masculine image of engineers historically positioned, it is also pervasive in modern professional engineering and engineering education. Research on stereotypes has found, "a general tendency, across every country investigated, that people on average have an easier

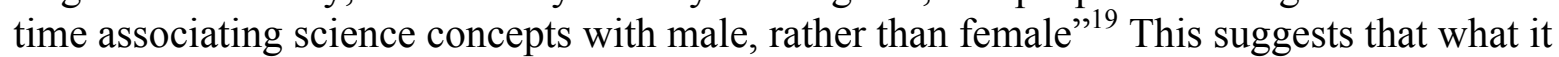
means to be female and what it means to be an engineer are mutually exclusive. When people speak of engineers, there is an instant and unconscious mental image of the typical engineer, namely male, unless it has been otherwise noted as a "female engineer" therefore exhibiting the "archetypically masculine culture" of engineering. ${ }^{20}$

As women seek membership into the professional field of engineering, they have to "fit in to a masculine culture", a culture that is much more comfortable to men. It is a setting filled with internal and unspoken rules allowing the environment to continually reproduce itself regardless of outside influences. ${ }^{21}$ With the culture continuing to be predominately male, it stands that males have easier access into this culture than females, thus allowing the engineering environment to continually reproduce itself as predominantly male since being an engineer is more "gender authentic" for a man than for a woman in our culture. ${ }^{22}$ Passing for a "genderneutral engineer" does not work because the job of engineer is never gender-neutral even with perceptions of engineering changing all the time. ${ }^{23}$

\section{Purpose of Higher Education}

One of the main goals of undergraduate education in universities and colleges is to design an academic curriculum that will lead to success. Along this educational pathway students are exploring and developing their personal identity. This is especially true for traditional age students who spend their college years moving from adolescence into emerging adulthood. This development includes changes in cognitive development, specifically the cognitive structures college students use to make meaning of their world. ${ }^{24}$ The focus of cognitive development theory is not on what students know or believe, but on how they structure their knowledge and beliefs and part of this story involves self-authorship. ${ }^{25}$

Engineering students are not learning in a vacuum. They are not just individual learners; they are individual learners within larger institutional and cultural environments and contexts. How they view themselves is "inextricably intertwined with their views of self in relationship with others".

${ }^{26}$ These others can include those in close social and physical proximity as well as systems and 
ideas that structure culture and cultural norms as framed by Nespor. ${ }^{27}$ These structure culture and cultural norms include the masculine culture of engineering environments, the bias of scientific discourse, the dominant image of the male engineer, and the lack of female role models in engineering.

\section{Conceptual Framework}

Much of the previous research on women in science, math and engineering programs has used large data sets and regression analysis in order to find specific factors and variables to predict female attrition in engineering. ${ }^{28}$ A large body of empirical research on women in science has focused on gender as being a fixed and fundamental aspect of one's identity causing gender to be one of many independent variables investigated to determine whether it causes an effect of retention or attrition. ${ }^{29}$ These studies assume the gender neutrality of technology as well as sustaining the dichotomy of women and men as homogenous, yet oppositional categories. These assumptions lead to a "one size fits all" mode of thinking when developing strategies for the recruitment and retention of women in engineering programs. ${ }^{30}$

In contrast, this research builds upon work calling for a greater understanding of the gender "in" and "of" engineering. ${ }^{31}$ It "bends the silos" (of individual academic disciplines) by utilizing theories, concepts, and methods from various disciplines to show that being successful in the engineering disciplines involves more than just mastering curriculum and technical competencies. It also involves learning how to be an active part of a learning community and negotiating one's personal psychosocial identity as one's "engineering identity" is also being developed.

The purpose of this study is to ask distinctive questions in order to gain greater understanding of the importance of the individual and how they develop an authentic and personal identity while managing the vicissitudes and uncertainties in a technological environment. The acknowledgement of the mutual shaping of gender and technology calls for research to be conducted on an ethnographic level permitting students to articulate their experiences in their own words and voices thus allowing for nuanced of meaning and understanding to emerge. Thus the primary questions guiding this research are:

1. How do female undergraduate engineering students perceive and negotiate their gender identities in relation to the institutional and cultural influences in their environment to successfully persist in engineering education?

2. How do perceptions and development of gender identity influence female engineering students regarding their professional choices?

\section{Theory of Self-Authorship}

Baxter Magolda's theory of self-authorship, ${ }^{26}$ describes the identity development of individuals as being capable of constructing their own perspectives by judging various evidences, both internal and external, and within context. Individuals have the ability to create their own autobiographies. This moves beyond the blind acceptance of truth and knowledge presented by sources and authorities outside of themselves. Self-authorship allows students a personal sense of agency in the process of self-authoring. 
Baxter Magolda introduces a developmental continuum that is an appropriate model to consider in this analysis because of its focus on the interpersonal, the intrapersonal and the epistemological aspects of individual students as well as its recognition of different gender patterns evident in students' pathway to self-authoring. Baxter Magolda describes the identity development of individuals as being capable of creating their own autobiographies moving beyond the blind acceptance of truth and knowledge presented by sources and authorities outside themselves while answering the interwoven questions of "Who am I?" (intrapersonal); "How do I want to construct relationships with others?" (interpersonal); and "How do I know?" (epistemological).

There are four phases on the route to self-authorship. The first is Following Formulas. This is when students believe they should follow the plans that have been laid out for them by external voices of authority. They allow others to define who they are, including parents, teachers, social norms and expectations, peers, etc. The second phase is Crossroads. This is when students realize that following the plans others have set before them may not necessarily match their own interests and desires and they become discontented with allowing others to define who they are, and they begin to create their own sense of self that is preferably more authentic. Yet, while students want to become more true to themselves, at this phase, they are exceedingly concerned with how others will react to their decisions and the effects on their relationships. These relationships include authority figures such as faculty and parents, as well as peers. The third phase of this theory is Becoming Author of One's Life. As the name implies, this phase is when the individual student develops the ability to choose their own beliefs, value, and direction for their lives, but many times must defend this individual authenticity against conflicting external voices and influences. Many times staying true to one's ideals and beliefs through living them out can be difficult. This phase encompasses a great amount of self-reflection and renegotiation as the student balances their personal needs and desires with those around them. This is one phase where the three components (epistemological, intrapersonal, and interpersonal) are very tightly intertwined. The final phase of this theory is Internal Foundation. Students who effectively realize this stage have shaped a strong foundation with an authentic sense of who they are (intrapersonal), a like-mindedness in their relationships both personally and professionally (interpersonal), and a personally defined belief system that allows for uncertainty and adjustments (epistemological). In this phase, students take into consideration external voices, but they trust their own feelings and cogently act on them. When individuals learn to trust their internal voice, they are better able to build internal foundations.

It is important to stress that this theory of self-authorship is not linear and Baxter Magolda concluded that while students were not identified as reaching self-authorship when they left university, they did have an initial awareness of the validity of inner voices in their lives and this awareness developmentally increases as students make meaning in their lives continuing towards an authentic identity that encompasses the interpersonal, intrapersonal and epistemological.

Baxter Magolda's theory of self-authorship provides the conceptual framework with inductive analysis used as the primary tool for data analysis. By utilizing the theory of self-authorship the theme of female engineering students career goals and aspirations and their developmental growth will be expounded upon. The females in this study are developing epistemologically, 
alongside endeavoring to acquire the power to generate and author their own truths as they listen to external voices of authority (including female engineering faculty) when determining for themselves what future paths to pursue. Becoming an engineer involves more than just pursuing a career, for females it also includes added expectations of continuing the legacy started by female engineering pioneers years ago.

\section{Methods}

This current research drawn from a larger four-year ethnographic case study of an undergraduate engineering program at a land grant Research I institution located in a region recognized for its shortage of engineering, looks at the individual through lenses of context and institution, as well as larger cultural paradigms. The thirty-four participants (twenty females, fourteen males), recruited through purposeful network sampling, were traditional-age junior- and senior-level engineering students carrying average GPA's, involved in various levels of campus leadership, and representative of six engineering disciplines (civil, electrical, mechanical, chemical, biosystems and mining).

A series of semi-structured interviews, each ranging from 90 to 140 minutes in length, was conducted with each participant. Interviews ceased when data saturation was reached. That is, when no new information surfaced during data collection and the researcher started to "see or hear the same things over and over again". ${ }^{32}$ Audio recordings of the interviews were transcribed.

During the academic year, study participants were observed in different settings, including formal gatherings (e.g., classes) as well as informal gatherings (e.g., in student commons) area. Communication with the participants continued through using e-mail communications and social networking sites in order to represent the students and their experiences and not become an "interpreter" of their experiences for others. ${ }^{33}$ The purpose of participant observation was to better understand how the students make sense of their environment and how the environment influences students. Culturally gendered activities that seemed to be unnoticed by the participants were observed throughout this phase.

The interview data was contextualized by an analysis of data collection of informal surveys given throughout the project, recruitment literature, magazines, websites, curriculum, and other publications designed to encourage females to enter into the engineering and technology fields as career options. Analyzing these documents allowed for the interviews to be placed in context within the specific institutional setting as well as the larger cultural environment regarding engineering. ${ }^{33}$

Analysis of the interview transcripts, notes taken during the interview, observation field notes, and artifacts were used to create broad analytic categories. As these categories were constructed, "member checking" was utilized with the study participants ensuring the categories and frameworks having some relation to the perspectives, understandings and experiences of those whose actions are analyzed, thus passing the validity test as the multiplicity of accounts required "navigat[ion] among the perspectives and contradictions represented". ${ }^{34}$ Inductive analysis including data reduction, data display, concept mapping, and verification was utilized to assure 
well-defined systematic, rigorous data collection, organization, and analysis procedures. ${ }^{33}$ As salient themes began to emerge, more complex coding schemes were created to sort and define the data applicable to the project. The data analysis for this study was iterative, systematic, and emergent. ${ }^{35}$ Cautious interpretation was conducted as potential explanations and possible patterns were sought through close reading and constant comparison of the data throughout the analysis process, verifying the results are "grounded" in the data. After once more conferring with participants on the accuracy of the interpretations, a revised summary with supportive excerpts from interviews and field notes were written resulting in the research findings.

\section{Findings}

\section{Why do they come? - Following Formulas}

Most students begin college by following the paths that have been laid out for them by others; this includes their choices in majors and careers. Many of their decisions "revolve around doing what one is supposed to do to be successful". ${ }^{36}$ Because these decisions are made by outside influences, they do not always fit with the students' actual desires or interests. They tend to disregard their own personal experiences and opinions. These influential voices can include those of teachers, parents, religious leaders, media figures, other adult engineers and traditional societal roles. These are the authoritative voices being heard by the females in this study and they believe these perspectives have certain and absolute knowledge, so it seems there was little room for personal agency in their choices.

While there are as many deviations to the educational paths as there are students I spoke with, there are also some striking similarities. The main similarities are the female participants' reputations as stellar students and their superior proficiency in math and science. All the female students mentioned they were "good in math and science" in middle school and high school. They spoke in more length and depth about their abilities and interests in math and science, than the male students, dispelling the myth that girls are not qualified or interested in studying math and science. ${ }^{37}$ One CME major explains how she began to be noticed by her teachers and peers in high school when she began to excel at math and science. She states, "I was good at English and everything else too, but a lot of people are good at English and everything else, so you really stand out if you're good at math and science." This common sense of pride in being good at math and science is strikingly pervasive among female engineering students. ${ }^{38}$

For some of the women, their abilities were celebrated even in middle school. One female mining engineering student talks about a teacher who let her work on math workbooks at least one or two grade levels above her initial level. Another female mechanical engineering major describes her teachers allowing her to double her science classes in middle school because she loved science so much and did well in those classes.

As many of the students describe their path to the College of Engineering, they talk about other family members who were engineers. Research shows having a family connection in engineering is a major influencing factor on females choosing an engineering career path. ${ }^{38}$ The women in this study were no different. Seven of the women spoke about discussing the possibilities of 
pursuing an engineering career with their immediate and extended family members who were also engineers.

For most of the women, choosing to study engineering was a conscious and complicated choice. One student talks about how she was told that because she was good at math she needed to pursue engineering, even though she describes it as a "shock" when a girl actually chooses engineering. She explains the shock is both on the part of the girl, as well as her friends and family. Another female contrasts this with the lack of effort it takes for males to choose engineering, "I don't think there's a lot of effort in the decision for a guy to be an engineer like there is for a girl because it seems more natural for guys." A male electrical engineering student explains this as, "Males go into engineering because they feel it's the masculine thing to do and it feels familiar." The females typically needed to have an explanation for why they chose engineering where the men did not because it is seemed more "normal" for them.

The voices of influence for the women in this study were both parents and family members who were engineers encouraging their daughters to pursue the profession, but even more influential was the women's understanding from their surrounding authority figures it was the best choice for females who are good at math and science.

\section{Why do they stay? - Crossroads}

With engineering being so difficult both in the curriculum and the environment, why do females stay? As they enter the Crossroads stage, they are hearing from other voices including those of their peers and engineering faculty, especially the female engineering faculty, but their internal voice is also gaining validity. Many times what they hear from others, and what they feel themselves is conflicting as well as complex, and depending upon the weight of validity given to each of these voices determines whether a female will stay in engineering. This may be one influential reason why many females leave engineering programs during their second year. Each female explained her investment in the program and her need to finish what she started and having other females in the program "talk her off the ledge". All of the females described the great need for support if a female is going to survive engineering and fight the "daily battles that come [their] way".

As the women talked about their career paths, it was evident many of them were struggling with listening to the external voices of authority as they are determining for themselves what career paths to pursue. This was especially evident when those voices were of the female engineering faculty. Students often mentioned how faculty would remind them of the myriad of prospects opened up to them as graduates from an engineering program. This extra pressure as described by one woman how a meeting with an advisor could become problematic if the student does not feel the same way.

She [advisor] is very dedicated to her work and she's very busy all the time. I would come into her office and not have my life together and planned out that I was going to "own" NASA in 25 years and she would look at me like I was nuts. She would explain all of the amazing and different things I could do when I graduated. She didn't know what to do with me because I'm not really sure I want to be an ENGINEER! 
For females there is the added expectation in this process of continuing the legacy started by female engineering pioneers so many years ago. One student explained how many professional female engineers see the female students as the next generation of women who are going to further the cause of women's equality in engineering.

These female students are also surrounded by the cultural norms that designate engineering as a masculine domain. When people speak of engineers, there is an instant and unconscious mental image of the typical engineer, namely male, unless it has been otherwise noted as a "female engineer. A female student notes this obliviousness:

When you say it as an engineer who's a woman, you say it as an after fact. [It's like] she's all these things, and oh by the way, she's a woman - like she's a subengineer or a junior varsity engineer and not really a professional. No one talks about an engineer and then says, 'oh by the way, he's a man' because it's already assumed.

The women are hearing the voices of those in authority in their education and attempting to combine the opinions of their faculty regarding what women in engineering should do with their own opinions and perspectives of what they personally desire to do. It is a difficult position to be in with the added pressure of legacy and feeling that by not continuing on in engineering they are somehow letting all women down.

As students continued to discuss their experiences, I asked the women if they had any desires to quit. I was surprised at the immediate and fervent responses I received in the affirmative:

"Every day I think why am I here? Why am I an engineer? But I'm at the point to where what would I do if I didn't do this?"

"Every day I have to consider the next scenario and ready myself for a different battle in different settings and it gets tiring."

"There are so many days when I think about quitting, but I'm halfway there and I'm not leaving now."

"I started as a mechanical engineering major and I'm finishing as a mechanical engineering major, not that I didn't try to "jump ship" quite a few times. I had some crises."

Nevertheless, each woman explains her investment in the program and her need to finish what she started. It is fair to say these women are resilient. They demonstrate this resiliency not only by their choice of a non-traditional major, but by their ability to not let the difficult gendered environment in engineering hinder their success. ${ }^{39}$

It seems they are fully integrated into the academic curriculum but not fully enrolled in the network of engineering. ${ }^{40}$ The way the curricular program is laid out, it does not succeed in preparing women to be "engineers-in-the-making", it seems there is something missing. While the women do feel a sense of belonging in their academic program, they seem to expend great effort and energy and yet do not feel fully included and personally authentic when contemplating entering into engineering professionally. 


\section{Why leave engineering? - Becoming the Author of One's Life}

As students continue through the Crossroads phase, a clearer and more personally authentic sense of direction begins to emerge. With graduation looming closer for these women, I asked them what they wanted to accomplish with their engineering degrees. I had assumed they would all want to pursue engineering careers to fulfill the goals they stated earlier, but I was wrong. The answers varied tremendously. A few female students discussed wanting to work for awhile in engineering and then going back to school to get an education degree, to teach math or science in a high school. One female discussed her dream of opening up her own coffee shop. Another woman described how she would have gotten her degree in Library Science if she had known it existed before she began her engineering courses.

Through an informal survey conducted in year three of this project, I received an assortment of answers when I asked women engineering majors what they pictured themselves doing in the next five to fifteen years. There was a lot of variety in their answers including: working somewhere (engineering or non-engineering) part-time, going into the ministry, being an equine surgeon, getting married and being a stay-at-home mom, being a "super-mom" (i.e. PTA, Girl Scout Leader, Class Mom), opening a bakery and becoming a florist. One senior explained she only wants to be an engineer long enough to earn money to put her kids through college and then she wants to stop and do something else.

One of the students interviewed states how she and her friends view engineering as "just something I'm going to do until I have babies." This mining engineering major explains how you can do well in engineering, but "you will have to think about your family some day and how it [career] will effect your kids growing up." She describes some engineering alumni who worked for a few years and then quit and "just became a mom." While some of the females in the study saw themselves as stay-at-home mothers and primary caretakers of their children, they were adamant about how their engineering degree would serve to help them to be better mothers.

These findings show the various conflicting issues that female engineering students are wrestling with; demonstrating the intertwining of the three components (epistemological, intrapersonal, and interpersonal) of this developmental phase. Though these issues were not even mentioned by the male engineering students female students discussed in great detail what they were "giving up" in order to pursue an engineering degree. These sacrifices included romantic relationships, authentic presentations of self and pursuits of other outside interests as described in other components of the larger research project. This demonstrates some of the additional developmental work that females in engineering must pursue along with an already rigorous academic curriculum. Due to the constraints of this paper, that topic will need to be dealt with at a different time.

\section{What do they choose? - Internal Foundation}

So the women are choosing to stay and be successful in engineering education but why they are not necessarily choosing to stay to be successful in professional engineering? Most of the women I spoke with talk about the ability to do anything with an engineering degree. One student 
explains how her ME degree is "a good for anything degree. I can do whatever I want with it. I can work at a university, be a politician, or be a mom."

They also saw the importance of females being in engineering. They believe that females have different, but legitimate qualities needed in the field of engineering including different skill sets. The females in the study view the problem with engineering is that the profession does not acknowledge the importance of those skills within the field. Even though many of the ways of thinking and doing that are stereotypically thought of as feminine are useful to technological work. As one female explains:

There are engineers who are very technically focused and want to be the subject matter experts and just do what they want to do. Then there are those people who want to do engineering and go up the ladder and be in management. There are different skill sets required for that in today's society it's all teamwork and working in groups. While you can still be technically focused you still have to have people skills.

By striving to have engineering more inclusive, and not so focused on the technical aspect, more women will feel they belong in the profession and their valuable talent will not be lost. One ME student, in discussing how to attract more talented women into engineering, presents other skills women can bring to the profession:

What engineering is really, is the ability to innovate. It is creativity and thinking outside the box. These are things girls are much better at than they give themselves credit for. It is critical thinking. The same critical thinking that allows you to write a coherent essay and people don't realize that. They think engineering is all math and science and so we're pushing good people away.

For most of the women I talked to, while they do not like a lot of what surrounds engineering, such as the gender stresses of their environment, ${ }^{41}$ they just love the practice of engineering and find pleasure in their work. Many of the women do not want to quit their major because they believe they have legitimate and necessary skills and talents they can contribute that belong in the field of engineering.

\section{Discussion}

It can be reasoned that these women are still leading their lives in deference to external structures and scripts outside of themselves. By following the more traditionally female career pathways (e.g., education, stay-at-home mom, etc.), it could be argued that these women are being guided by the strong societal voices working to keep women out of the engineering workforce, referring back to the initial phase of "Following Formulas". Yet, these women are making personal choices in their education and work to negotiate the "complex interconnection discourses concerning the relationship between gender, sexuality, and work". ${ }^{2}$ This demonstrates how the females in this study are moving into self-authorship of their lives as evidenced by their abilities to contend with the opposing voices they have experienced all through their time at the College of Engineering:

- They have been told to become more masculine while at the same time they have been told to be more feminine. 
- They have been told engineering is "man's work", while being told "women can be engineers too."

- They have listened to conflicting viewpoints, all the while learning an extremely difficult discipline.

Because most of these women envelop themselves in their peer culture for support, and talk to and observe many female engineers and engineering faculty as well as have the ability to make their opinions and views known, one can presume they are well on their way to self-authorship. Since autobiographical knowers integrate their construction of knowledge "via communion and agency" 43 it is evident these women are not making their future career choices based on someone else's convictions. They may be following what could be determined as the traditional scripts society has set for females, but this is happening only after they have "bucked the system" in following a non-traditional major.

These female students are beginning to build their internal foundations by balancing the varied, and many times conflicting external voices with their own inner voice. While this research continues longitudinally through follow-up interviews scheduled for three - years, postgraduation in 2013, some students have already changed their career paths as evidenced through social network contacts. As females develop personal and professional identities that are authentic, they experience feelings of peace, inner strength and contentment. ${ }^{44}$

A limitation of this research project is that the data represents only a western perspective on women in engineering. While the focus of this study was to understand women's experiences who had come through the American educational system, for further research it would be interesting to compare their experiences with women engineering students from countries where engineering education is defined differently and the pathway is more structured and objectively determined. This research is currently being continued in the Middle East region where females make up as much as $50 \%$ of the engineering students. There is increasing evidence that because of various religious and ethnic ideologies, as well as familial influences, more females, after graduating from university, do not continue on as professional engineers, but serve in more traditionally gendered roles and careers. As their perspectives might generate very different results, it is an important step in comparative engineering education research.

\section{Conclusion}

Engineering as an academic discipline results in a professional degree focusing on graduating engineers who are prepared to go into the workforce immediately after school. For women to make a difference as professional engineers, they must finish their engineering education, but what about those women who graduate who do not want to be engineers? If these women are achieving self-authorship, why are they not ultimately choosing professional engineering as a career choice? Could it be that the cultural symbols of engineering as a masculine field are so strong and constant that even as the female engineering students are successful in their academic major and have developed the ability to choose their own beliefs, value, and direction for their lives, they find they must defend this individual authenticity against the conflicting external voices and influences? As stated earlier, many times staying true to one's ideals and beliefs through living them out can be difficult. As one student said, "I can fight the [gender] battles until graduation - but I don't want to do this for the rest of my life - I'm already too tired." 
No matter how many women come into engineering education, it seems that unless the dominant masculine discourse is changed within the educational environment, the increase of women into professional engineering careers will be fleeting at best. On campus, policies which directly support female success including various student organizations and hiring more female faculty are needed and curricular reforms designed to deconstruct the dichotomy between "soft" and "hard" technical skills are important as a way to address the social construction of technology as masculine. Policy implications of this study also go beyond the university setting to include suggestions for ways that professional engineering organizations might recognize the gendered nature of the internship and co-op processes.

Effective engineering education is strategic in supporting all students to achieve authentic identity development alongside increasing their technical skills. When students believe their personality and skills are good matches for their environment, their self-efficacy and commitment to their academic and professional environment increases. Recognizing the complexity of gender concerns within engineering education and the larger engineering culture will assist in "stemming the tide" 45 by challenging the masculine paradigm of engineering to be transformed.

\section{Bibliography}

1. Henwood, F. (1998). Engineering difference: Discourses on gender, sexuality and work in a college of technology. Gender \& Education, 10(1), 35 - 49.

2. Acker, S. (1994). Gendered education: Sociological reflections on women, teaching, and feminism. Philadelphia, PA: Open University Press.

3. Baxter Magolda, M. (2001). Making their own way: Narratives for transforming higher education to promote selfdevelopment. Sterling, VA: Stylus

4. Beede, D.,Julian, T., Langdon, D., McKittrick, G., Kahn, B., and Doms, M. 2011. "Women in STEM: A Gender Gap to Innovation". Economics and Statistics Administration (ESA) Issue Brief 04-11 (August 2011). U.S. Department of Commerce, Washington D.C. http://www.esa.doc.gov/sites/default/files/reports/documents/womeninstemagaptoinnovation8311.pdf.

5. National Science Foundation, Division of Science Resources Statistics. 2011. Women, Minorities, and Persons with Disabilities in Science and Engineering: 2011. Special Report NSF 11-309. Arlington, VA: National Science Foundation. http://www.nsf.gov/statistics/wmpd/.

6. Lawal, I. (2007). Proceedings from ASEE Annual Conference and Exposition 2007: Women in science and engineering: Politics of gender. Honolulu, HI: ASEE.

7. Bijker, W.E. and J. Law. 1994. Shaping Technology/Building Society: Studies in Sociotechnical Change. Cambridge, MA: MIT Press.

8. Bix, A. S. (2000). Engineeresses invade campus. IEEE Technology \& Society, 2, 20-26.

9. Ihsen, S. (2005). Special gender studies for engineering. European Journal of Engineering Education, 30(4), 487 494.

10. Lohan, M. (2000). Constructive tensions in feminist technology studies. Social Studies of Science, 30(6), 895 916.

11. West, C., \& Zimmerman, D.H. (1991). Doing gender. In J. Lorber and S.A. Farrell (Eds.) The social construction of gender (pp. 13 - 37). Thousand Oaks, CA: Sage Publications.

12. Butler, J. (1990). Gender trouble: Feminism and the subversion of identity. New York, NY: Routledge.

13. Hawkesworth, M. (1997). Confounding gender. Signs, 22(3), $649-684$.

14. Kidder, D.L. (2002). The influence of gender on the performance of organizational citizenship behaviors. Journal of Management, 28, $629-648$.

15. Clegg, S. (2008). Feminities/masculinities and a sense self: Thinking gendered academic identities and the intellectual self. Gender and Education, 20(3), $209-221$.

16. Kline, R.R. (2008). From progressivism to engineering studies: Edwin Layton's The Revolt of the Engineers. 
Technology and Culture, 49, $1018-1024$.

17. Tonso, K. L. (1996a). The impact of cultural norms on women. Journal of Engineering Education, 85(3), 217 225.

18. Kvande, E. (2002). Doing masculinities in organizational restructuring. NORA, 1(10), $16-23$.

19. Samarrai, F. (2009). Gender Gap. U.Va. College and Graduate School of Arts \& Sciences. Retrieved from http://aands.virginia.edu/x15919.xml.

20. Wajcman, J. (2000). Reflections on gender and technology studies: In what state is the art? Social Studies of Science, $30(3), 447-464$.

21. Lave, J., \& Wenger, E. (1991). Situated learning: Legitimate peripheral participation. New York, NY: Cambridge University Press.

22. Faulkner, W. (2007). "Nuts and bolts and people": Gender-troubled engineering identities. Social Studies of Science, 37(3), $331-356$.

23. Chachra, D., Kilgore, D., Loshbaugh, H., McCain, J., \& Chen, H. (2008). Proceedings from ASEE Annual Conference and Exposition 2008. Being and becoming: Gender and identity formation of engineering students. Pittsburgh, PA: ASEE.

24. Chickering, A.W., \& Reisser, L. (1993). Education and Identity ( $2^{\text {nd }}$ ed.). San Francisco, CA: Jossey-Bass.

25. King, P.M., \& Kitchner, K.S. (1994). Developing reflective judgment: Understanding and promoting intellectual growth and critical thinking in adolescents and adults. San Francisco, CA: Jossey-Bass.

26. Baxter Magolda, M. B. (1999). Creating contexts for learning and self-authorship: Constructive-developmental pedagogy. Nashville, TN: Vanderbilt University Press.

27. Nespor, J.A. (1994). Knowledge in motion: Space, time and curriculum in undergraduate physics and management. Bristol, PA: The Falmer Press.

28. Hyde, M.S., \& Gess-Newsome, J. (1999). Adjusting educational practice to increase female persistence in the sciences. Journal of College Student Retention, 1(4), 335 - 355.

29. Markwick, K. (2006). Under the feminist post-structuralist lens: Women in computing education. Journal of Educational Computing Research, 34(3), 257 - 279.

30. Phipps, A. (2007). Re-inscribing gender binaries: Deconstructing the dominant discourse around women's equality in science, engineering, and technology. Sociological Review, 55(4), 768 - 787.

31. Faulkner, W. (2007). "Nuts and bolts and people": Gender-troubled engineering identities. Social Studies of Science, 37(3), $331-356$.

32. Merriam, S.B. (2002). Qualitative research in practice: Examples for discussion and analysis. San Francisco: Jossey-Bass.

33. Miles, M.B., \& Huberman, A. M. (1984). Drawing valid meaning from qualitative data: Toward a shared craft. Educational Researcher, 13(5), 20 - 30.

34. Talburt, S. (2004). Ethnographic responsibility without the "real". The Journal of Higher Education 75 (1). 80 103.

35. Patton, M.Q. (2002). Qualitative education and research methods ( ${ }^{\text {rd }}$ ed.). Newbury Park, CA: Sage.

36. Baxter Magolda, M. (2001). Making their own way: Narratives for transforming higher education to promote selfdevelopment. Sterling, VA: Stylus. p.78.

37. Galloway, P. D. (2007). The $21^{\text {st }}$-Century engineer: A proposal for engineering education reform. Reston, VA: American Society of Civil Engineers.

38. Gill, J., Mills, J., Franzway, S., \& Sharp, R. (2008). 'Oh you must be very clever!': High achieving women, professional power and the ongoing negotiation of workplace identity. Gender and Education, $20(3), 223$ - 236.

39. Morris, L.K., \& Daniel, L.G.(2008). Perceptions of a chilly climate: Differences in traditional and non-traditional majors for women. Research in Higher Education, 49(3), 256 - 273.

40. Tinto, V. (1988). Stages of student departure: Reflections on the longitudinal character of student leaving. The Journal of Higher Education, 59(4), 438 - 455.

41. Evetts, J. (1998). Managing the technology but not the organization: Women and career in engineering. Women in Management Review, 13(8), 283 - 294.

42. Henwood, F. (1998). Engineering difference: Discourses on gender, sexuality and work in a college of technology. Gender \& Education, 10(1), 35 - 49. p. 38.

43. Baxter Magolda, M. B. (1999). Creating contexts for learning and self-authorship: Constructive-developmental pedagogy. Nashville, TN: Vanderbilt University Press. p.53.

44. Baxter Magolda, M. (2001). Making their own way: Narratives for transforming higher education to promote selfdevelopment. Sterling, VA: Stylus. p.78. 
45. Fouad, N. \& Singh, R. (2011). Stemming the Tide: Why women leave engineering. National Science Foundation ("Women's Persistence in Engineering Careers,: Contextual Barriers/Supports") NSF \# 0827553. Available at http://energy.gov/sites/prod/files/NSF_Stemming\%20the\%20Tide\%20Why\%20Women\%20Leave\%20Engineering. pdf. 